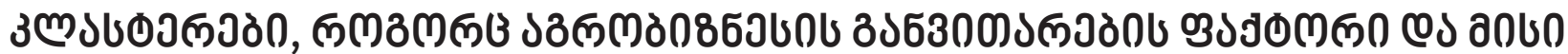

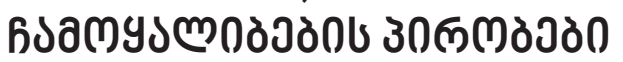

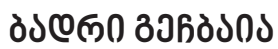

https://doi.org/10.35945/gb.2017.03.015

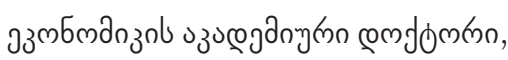

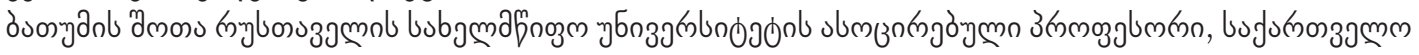

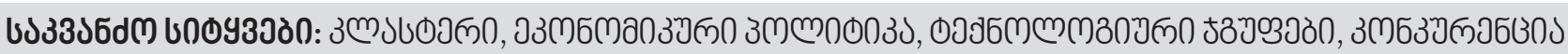

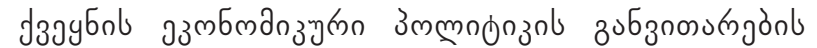

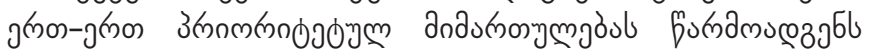

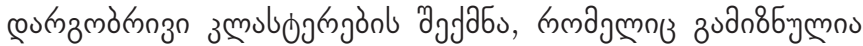

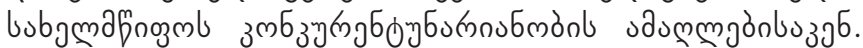

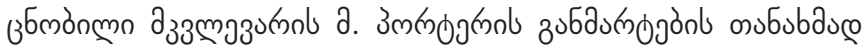

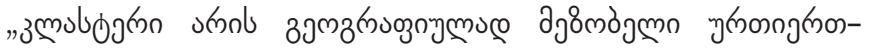

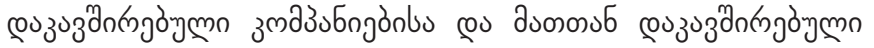

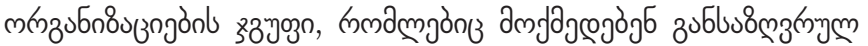

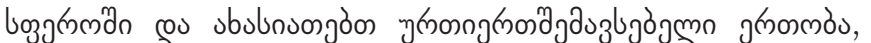

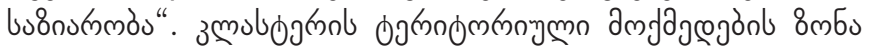

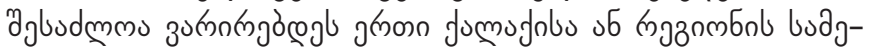

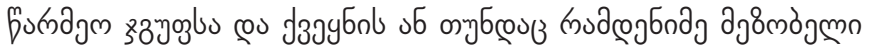

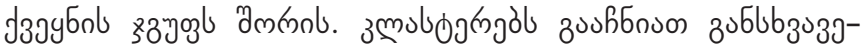

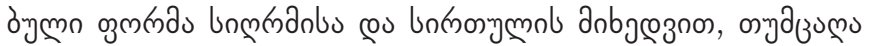

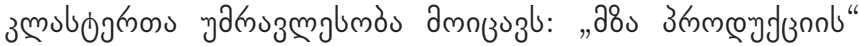

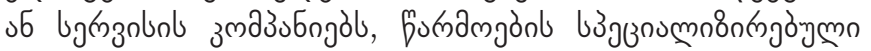

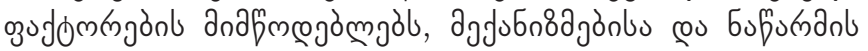

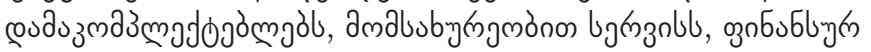

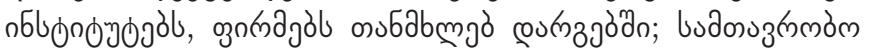

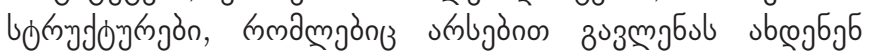
зmulog

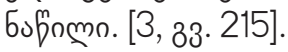

змб

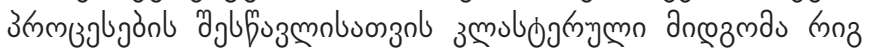

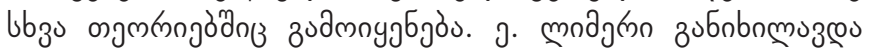

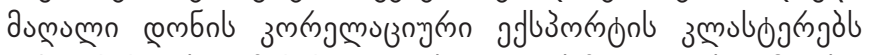

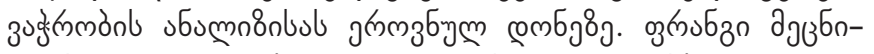

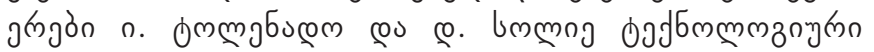

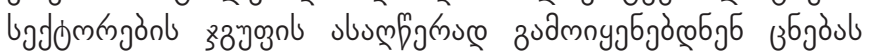

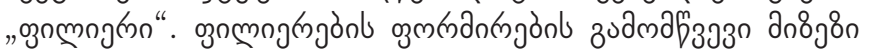

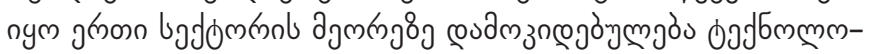

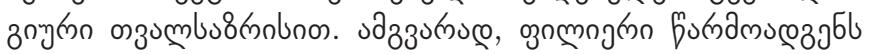

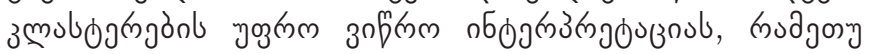

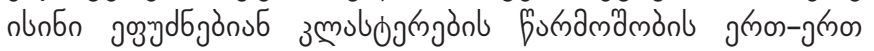

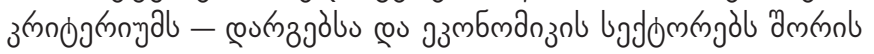

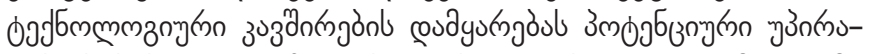

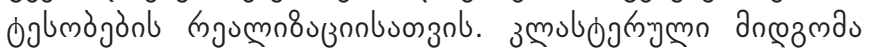

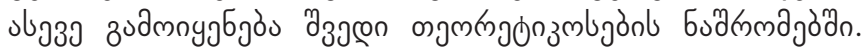
duon з змulb

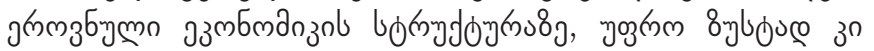

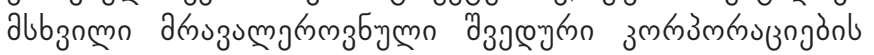

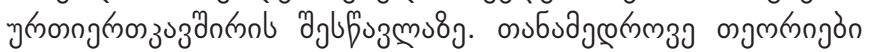

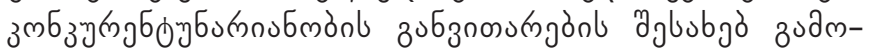

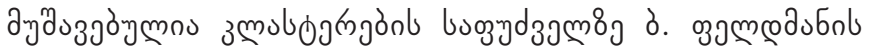

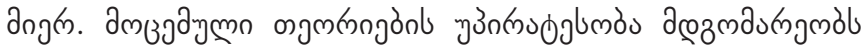

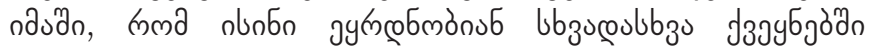

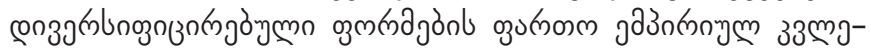
3job [5, 33. 35].

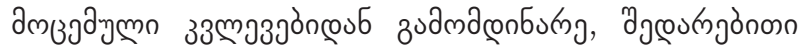

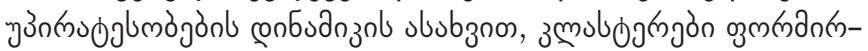

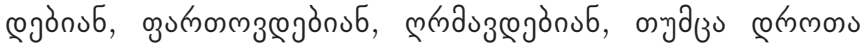

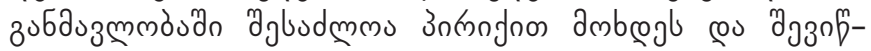

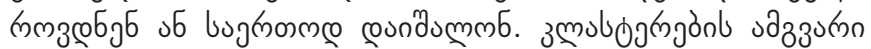

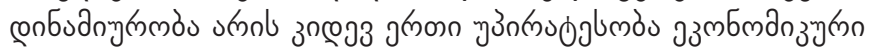

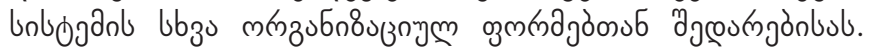

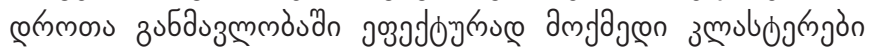

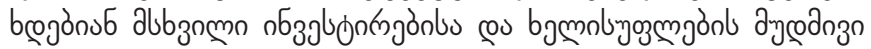

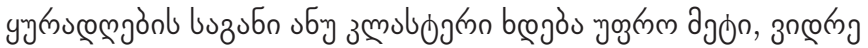

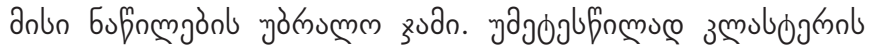

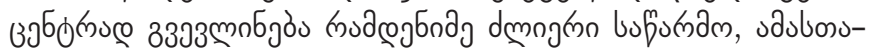

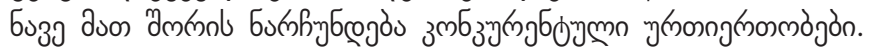
agdm dajönl, aynœ

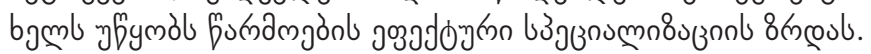

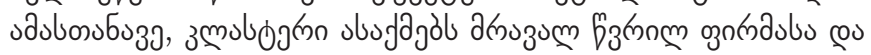

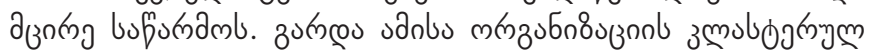

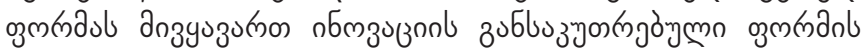

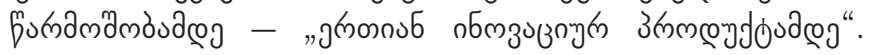

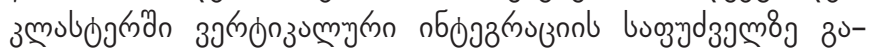

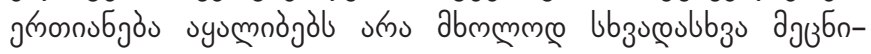

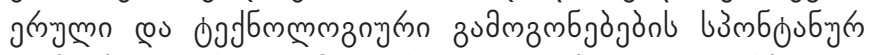

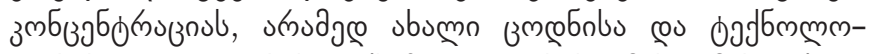

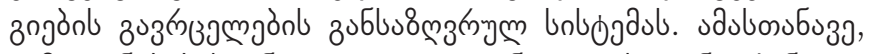

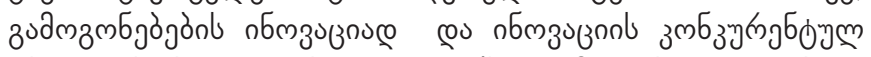

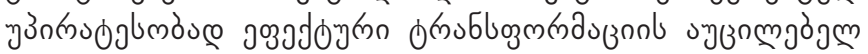

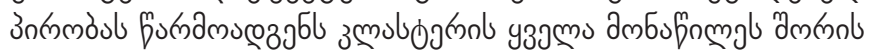

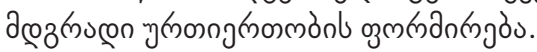

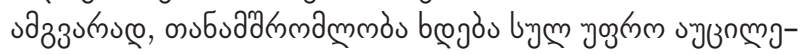

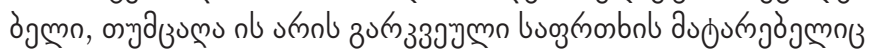

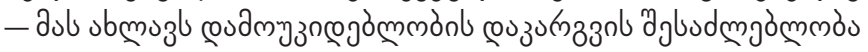

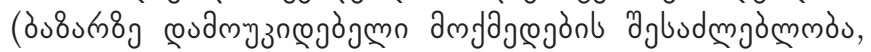

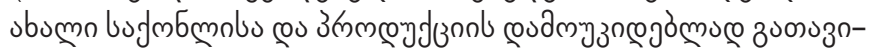
५

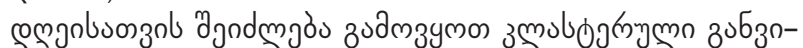

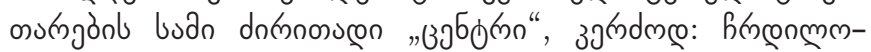

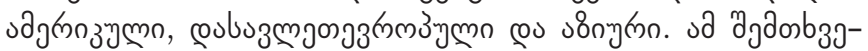

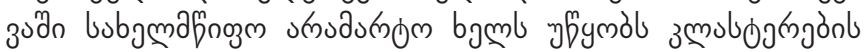

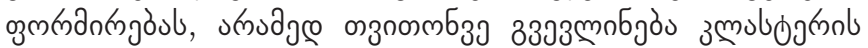

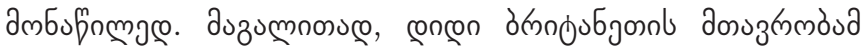




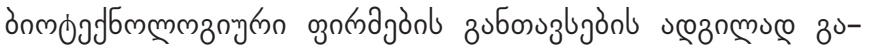

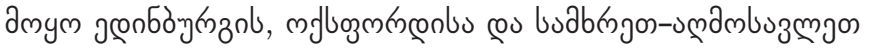

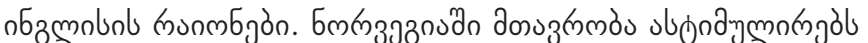

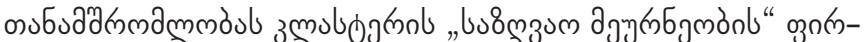

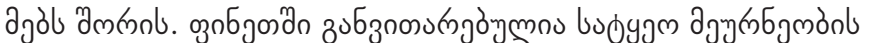

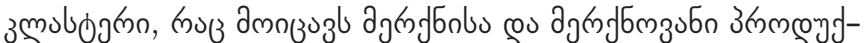

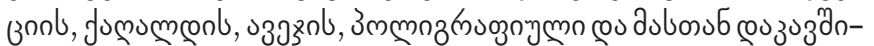

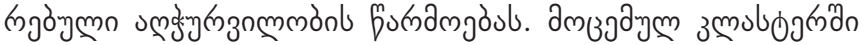

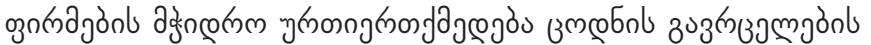

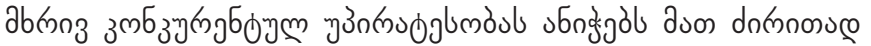

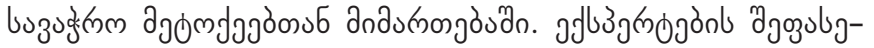

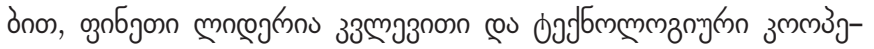
nozonl sombnon.

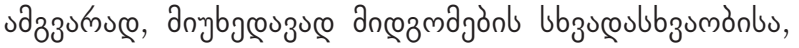

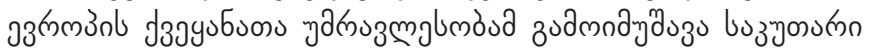

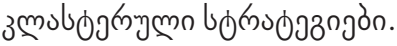

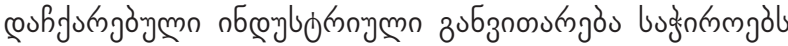

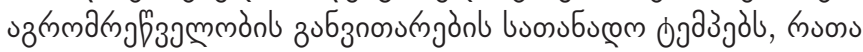

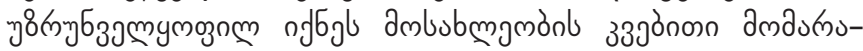

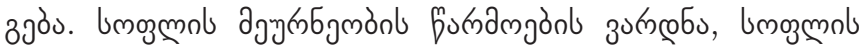

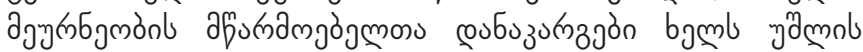

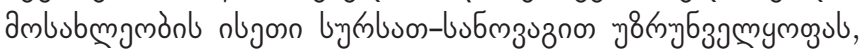

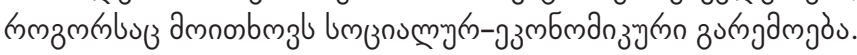

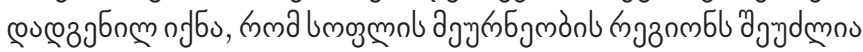

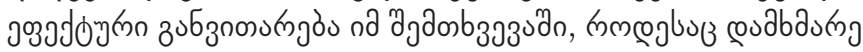
cu ambumglus

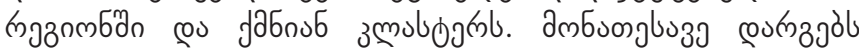

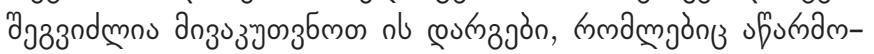

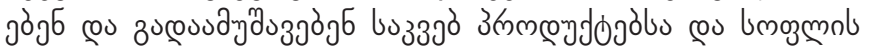

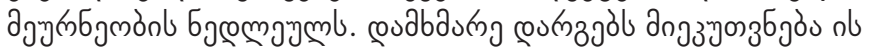

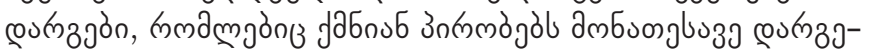

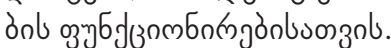

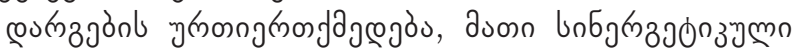

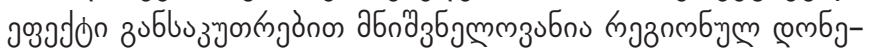

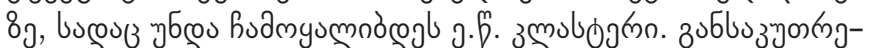

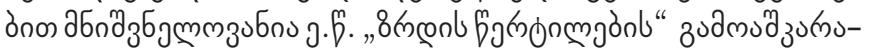

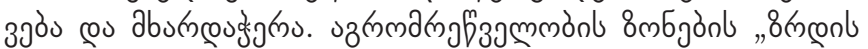

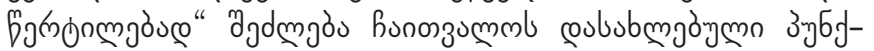

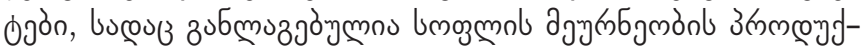

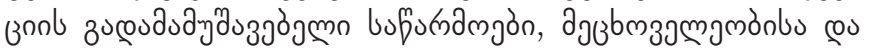

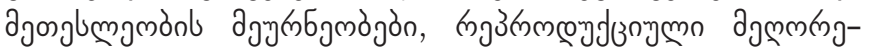

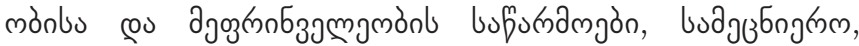

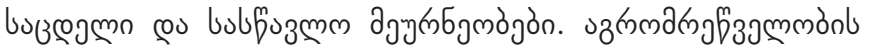

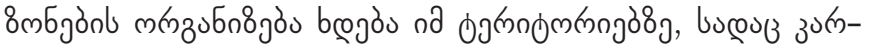

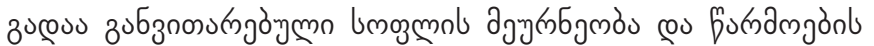

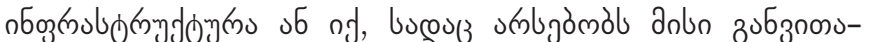

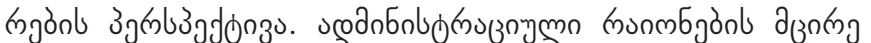

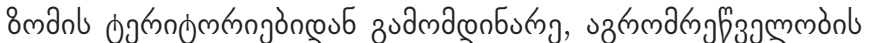
з mulu

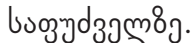

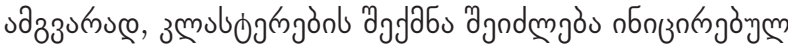

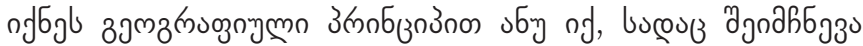

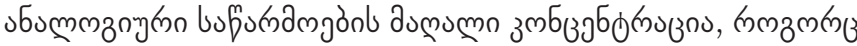

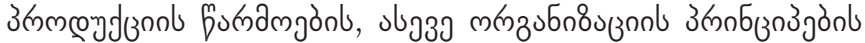

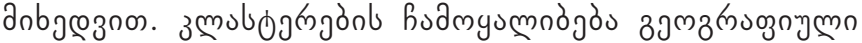

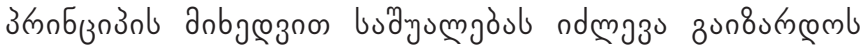

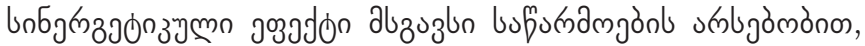

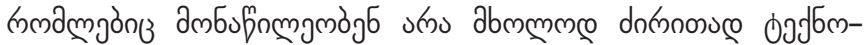

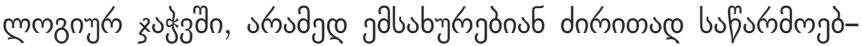

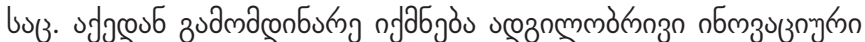

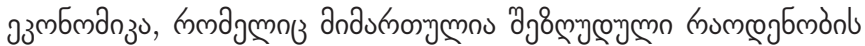

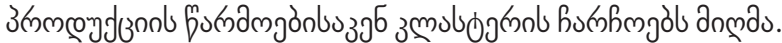

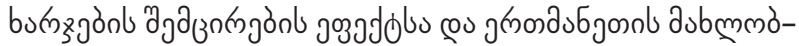

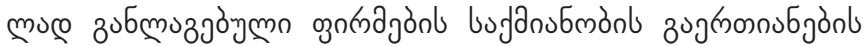

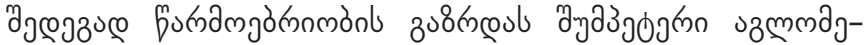

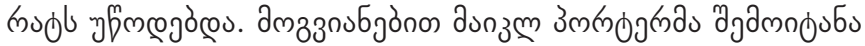

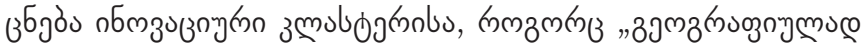

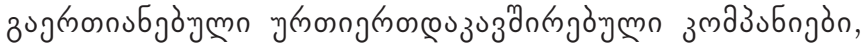

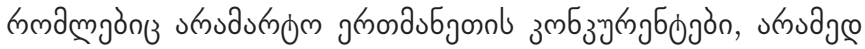

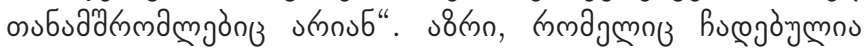

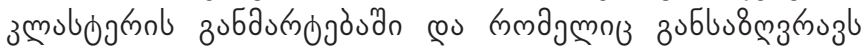

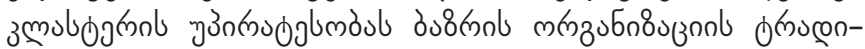

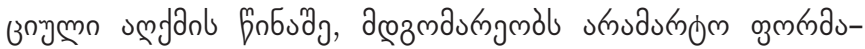

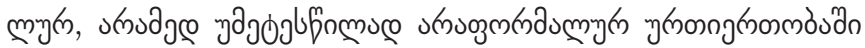

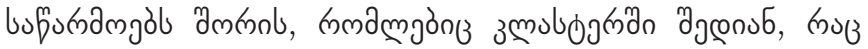

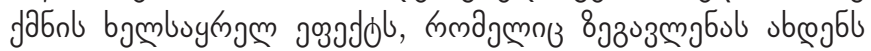

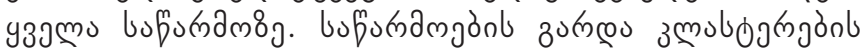

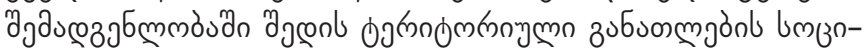

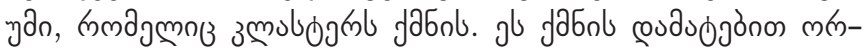

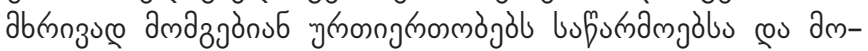

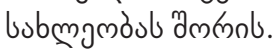

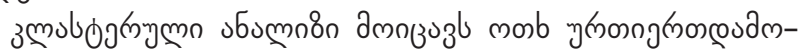

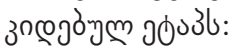

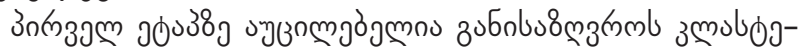

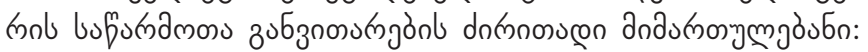

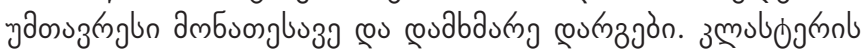

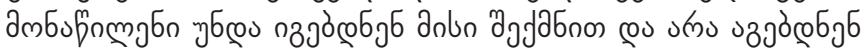
змб зचु

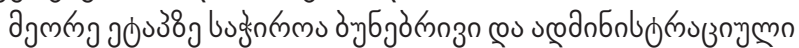

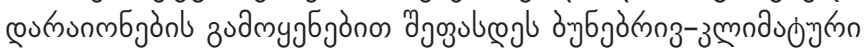

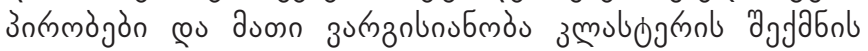
an86 jonbsomzol;

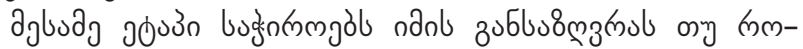

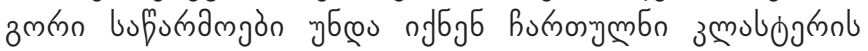

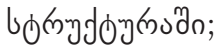

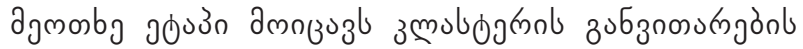

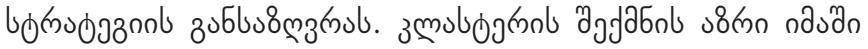

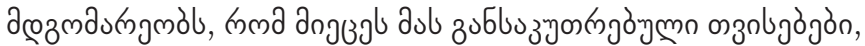

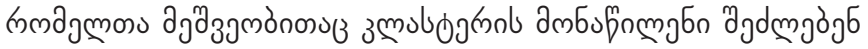

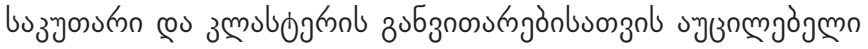
nбogm

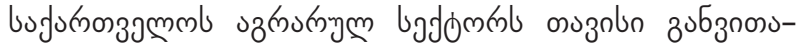

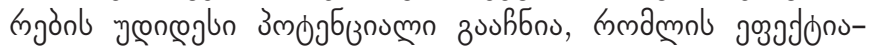

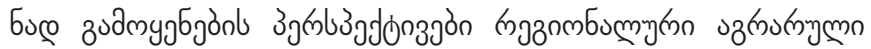

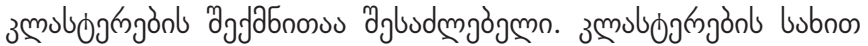

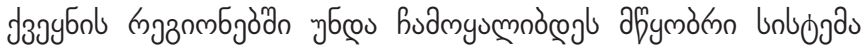




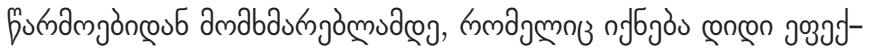

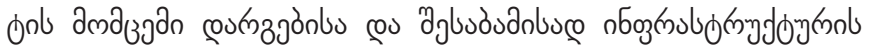

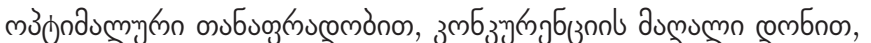

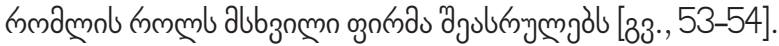

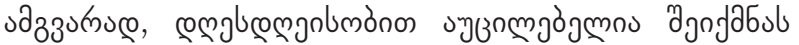

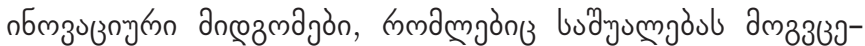

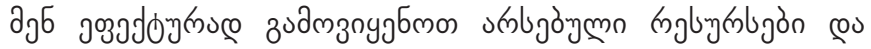

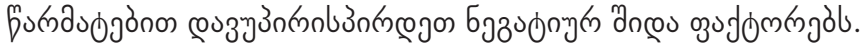

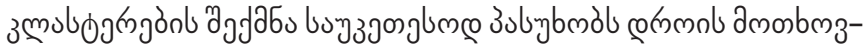

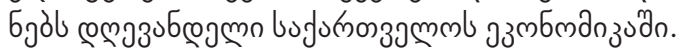

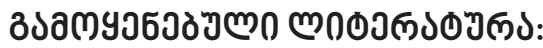

1. Шумпетер Й.А. Капитализм, социализм и демократия: Пер. сангл. / Под.ред. В.С. Автономова. - М.: Экономика, 1995. $-540 \mathrm{c}$.

2. Портер М.Э. Конкуренция: Пер. с англ.- М.: Вильямс, 2006. - 608 с.

3. Романова О.А., Лаврикова Ю.Г. Кластерное развитие экономики региона: теоретические возможности и практический опыт // Экономика региона. - 2007. - № 3. - С. 40-51.

4. Feldman V.P., Audretsch D.B. Innovation in Cities: Science based Diversity, Specialization and Localized Competition // European Economic Review. - 1999. - № 43. - P. 31 - 39.

5. Leamer E.E. Souses of International Comparative Advantage: Theory and Evidence // Cambridge, MIT Press, 1984.

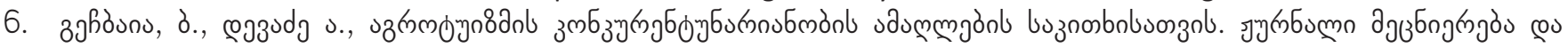

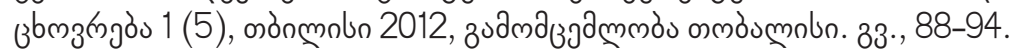

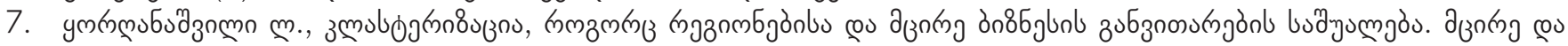

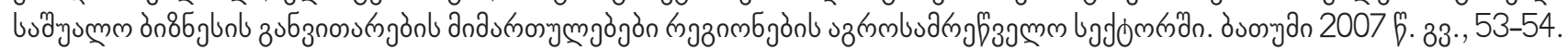

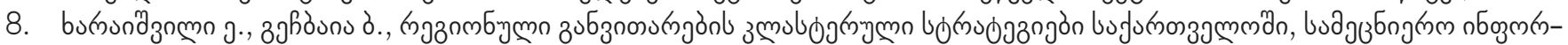

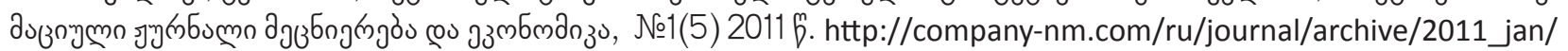




\section{CLUSTERS AS A FACTOR OF AGRIBUSINESS DEVELOPMENT AND CONDITIONS OF ITS FORMATION}

BADRI GECHBAIA

https://doi.org/10.35945/gb.2017.03.015

Academic Doctor of Economics,

Batumi Shota Rustaveli State University Associate Professor, Georgia

\section{KEYWORDS: CLUSTER, ECONOMIC POLICY, TECHNOLOGY GROUPS, COMPETITION}

\section{SUMMARY}

The rapid industrial development demands the corresponding rate of the agricultural development in order to ensure the reliable food supply for the population. The fall of the agricultural industry, the unprofitability of the agricultural producers do not allow to solve the mission of relia- ble food supply correspondingly with the social-economical situation.

It was stated that an agricultural region may be developed effectively only in case of more or less grouped system of supporting and relational branches that form the clusters in the region. 